\title{
Optimal stroke frequency during diving activity in seabirds
}

\author{
Yoshihisa Mori ${ }^{1, *}$, Akinori Takahashi ${ }^{2}$, Philip N. Trathan ${ }^{3}$, Yutaka Watanuki ${ }^{4}$ \\ ${ }^{1}$ Department of Animal Sciences, Teikyo University of Science \& Technology, 2525 Yatsusawa, Uenohara, \\ Yamanashi 409-0193, Japan \\ ${ }^{2}$ National Institute of Polar Research, Tachikawa, Tokyo 190-8518, Japan \\ ${ }^{3}$ British Antarctic Survey, Natural Environment Research Council, Cambridge CB3 0ET, UK \\ ${ }^{4}$ Graduate School of Fisheries Sciences, Hokkaido University, Minato-cho 3-1-1, Hakodate, Hokkaido 041-8611, Japan
}

\begin{abstract}
Diving animals have to counter both drag and buoyancy when moving through the water column. The magnitude of these forces depends upon an animal's swim speed and current depth. Feet, fins or flippers create a motivating force, and different stroke strategies give a variable level of output power, providing both fast swim speeds and reduced travel times to any given target depth. However, while feet, fins or flippers may confer a real advantage, they also create considerable drag and engender high metabolic (oxygen consumption) costs. Consequently, there should be an optimal relationship between output power and stroke frequency during diving. Here we develop diving models to predict the optimal pattern of stroke frequency during both the descent and ascent phase of divers in water, while maintaining a minimum cost of transport (COT, $\mathrm{J} \mathrm{kg}^{-1} \mathrm{~m}^{-1}$ ). We also test predictions derived from these models using diving data for foot-propelled South Georgian shags Phalacrocorax georgianus diving to deeper than $80 \mathrm{~m}$. Our predictions include: (1) output power (stroke frequency) should decline during the descent and ascent phases of a dive, but constant output power should be evident when the diving depth is shallow, (2) initial thrust for dives to deeper target depths should be smaller during the descent phase and greater during the ascent phase, and, (3) swim speed should be constant during the descent phase and should decrease first or remain constant, then increase during the ascent phase because of a declining output power strategy. Our empirical data on shags support only some of these predictions. Predictions (1) and (3) were supported by our observations, but Prediction (2) was not, possibly due to unknown but specific factors concerning diving seabirds. These findings suggest that diving seabirds adjust and control their stroke frequency pattern in order to minimize COT during diving, generating the observed changes in swimming speed.
\end{abstract}

KEY WORDS: Cost of transport $\cdot$ COT $\cdot$ Diving $\cdot$ Optimal model $\cdot$ Seabirds $\cdot$ Stroke frequency Resale or republication not permitted without written consent of the publisher

\section{INTRODUCTION}

Animals invest their time and energy in various activities in order to survive and reproduce, and this investment is critical for their fitness. In the context of foraging, animals are expected to behave efficiently by adjusting their foraging behaviour under given constraints in order to maximize an objective function such as net rate of energy gain (Stephens \& Krebs 1986, Stephens et al. 2007). Diving seabirds, such as penguins, alcids and cormorants, are air-breathing but forage in water where they cannot breathe. Since this limitation of oxygen is specific to and critical for diving seabirds, they should organize their diving behaviour optimally under the physiological constraints. Based on this constraint of oxygen, many authors have presented diving models that predict optimal dive cycle, dive depth and body size or optimal organization of dive bouts (e.g. Kramer 1988, Wilson \& Wilson 1988, Ydenberg \& Clark 1989, Houston \& Carbone 1992, Carbone \& Houston 1996, Mori 1998a,b, 1999, 2002a,b, Thompson \& Fedak 2001, Heithaus \& Frid 2003).

In addition to the limitation of oxygen, diving seabirds are faced with other difficulties while diving: 
they experience a large buoyant resistance, which decreases as birds descend (Lovvorn et al. 1991, Wilson et al. 1992), and they have to expend mechanical work to counteract drag as they travel through the water (Lovvorn 2001). Therefore, it is expected that diving seabirds adjust their diving behaviour against these difficulties to make their dives efficient. To travel through water, birds use strokes of either flipper, wing or foot, compensating for buoyancy and drag. By adjusting stroke frequency, diving seabirds can control output power for propulsion. High frequency stroke rates result in fast speeds that result in short time periods to reach a given target depth, but also generate greater drag and higher metabolic costs (oxygen consumption rate). Therefore, there should be an optimal pattern of output power or stroke frequency for diving. Several studies have shown that diving seabirds appear to regulate their stroke frequency during diving (e.g. van Dam et al. 2002, Lovvorn et al. 2004, Sato et al. 2005, Watanuki et al. 2005, 2006, Heath et al. 2006), by using small animal-borne devices that record acceleration as well as diving depth and duration or video cameras. Some theoretical models argue for optimal swimming speed or stroke patterns during diving (e.g. Wilson et al. 1992, Lovvorn et al. 1999, Lovvorn 2001). Using oxygen consumption rates of penguins while swimming horizontally at various speeds in shallow swim canals, some authors (e.g. Culik et al. 1991, Bethge et al. 1997) suggested that penguins swam at optimal swim speeds while maintaining minimum cost of transport (COT). However, the direct decision variables for the vertical movements of diving seabirds through water are those that affect regulation of stroke frequency rather than swim speed. It remains unknown how vertically diving seabirds adjust output power or stroke frequency during a dive under a set of given conditions.

In this paper, we develop diving models that predict optimal change of output power (stroke frequency) with current depth during vertical diving to achieve swim speed at minimal COT. We demonstrate the effects of target depth on the optimal stroke frequency patterns and optimal changes in swim speed during diving. Finally, we compare these predicted patterns with observed patterns. Although we focused on diving behaviour of seabirds, our model and approach can be used for other air-breathing diving animals.

\section{METHODS}

Models. General procedure: There are 4 forces acting on a diving animal moving through the water column; gravity, $F_{\mathrm{g}}$, buoyancy, $F_{\mathrm{b}}$, drag, $F_{\mathrm{d}}$, and thrust by stroke, $F_{\mathrm{s}}$. Assuming that the animal moves vertically with continuous and smooth output power control through the water, we obtain the following motion equation,

$$
F_{\mathrm{g}}+F_{\mathrm{b}}+F_{\mathrm{d}}+F_{\mathrm{s}}=m a
$$

where $m$ is mass of the animal and $a$ is acceleration. Note that if the animal moves obliquely and output power is neither continuous nor smooth, then other factors such as lift and inertia should affect the movement (e.g. Lovvorn 2001, Sato et al. 2005). The magnitude of buoyancy and drag depend upon the current depth and current speed, respectively, while gravity is $\mathrm{mg}$, where $g$ is acceleration of gravity. Therefore, motion in Eq. (1) can be expressed as

$$
m g+y[x(t)]+z\left[x^{\prime}(t)\right]+F_{\mathrm{s}}=m x^{\prime \prime}(t)
$$

where $x(t), x^{\prime}(t)$ and $x^{\prime \prime}(t)$ are current depth, speed and acceleration at time $t$, respectively. Using this differential equation, we can determine the depth and speed at time $t$ for a given thrust by stroke. The thrust by stroke during diving is determined by a decision made by the animal. Given a stroke frequency pattern (rule of change of the stroke frequency as a function of current depth) during descent and ascent, we can determine the total time and work (energy) needed to vertically move a distance (target depth) through the water for a given stroke frequency pattern.

We assume that the oxygen consumption rate for mechanical work (excluding basal metabolism) is proportional to the stroke output force and that animals minimize COT(cost of transport: energy consumed per unit distance during transport, $\mathrm{J} \mathrm{kg}^{-1} \mathrm{~m}^{-1}$ ). COT includes energy (mechanical work, $\mathrm{Nm}=\mathrm{J}$ ) to transport an animal to a given depth and the basic oxygen consumption, which is transformed to energy during the transport. Thus, an animal traveling a given distance using a strategy with a lower stroke frequency, may benefit from a low energy consumption rate for transport, but suffer from a large energy consumption for taking a longer time, and vice versa. Using a stroke frequency pattern as a function of the current depth, $x(t)$, and using an appropriate basal metabolic rate (BMR), we can calculate the COT for a given depth for a given stroke frequency pattern; this is feasible because we can obtain time and work (energy) consumed to move to a given depth using Eq. (2).

In practice, it is impossible to algebraically find the optimal stroke frequency pattern as a function of the current depth. Therefore, in the present study, we focus on 2 patterns (rules of regulation) of stroke frequency as a function of current depth; a constant stroke frequency irrespective of current depth (a constant output power strategy), and a declining stroke frequency with current depth while descending and ascending (a declining output power strategy). Ani- 
mals adopting the latter strategy may benefit from declining buoyancy while descending and increasing buoyancy while ascending. Using different functions to represent these 2 strategies, we sought optimal stroke frequency patterns in relation to current depths to minimize the COT for descending to and ascending from a given target depth.

Functions used in the model: (Table 1.) To simplify the calculation, we assumed that the body mass, $m$, is 1.0 in the model. We defined the following function as buoyancy (in N), $F_{\mathrm{b}}$ in Eq. (1) and $y[x(t)]$ in Eq. (2), at a depth of $x(t)$ :

$$
F_{\mathrm{b}}=8.5+7.5 /[1+0.1 \mathrm{x}(t)]
$$

(Fig. 1a) Although this was arbitrarily defined, the function used in Kato et al. (2006) to calculate buoyancy gives $9.86+5.6 /[1.0+0.1 x(t)]$ for body mass $=$ $1.0 \mathrm{~kg}$, following equations from Wilson et al. (1992). Lovvorn et al. (2004) also assumed buoyancy of Brünnich's guillemots Uria lomvia as 5.1/[1 + $0.1 x(t)]-0.62$, including gravity, suggesting that the definitions used in the present study are reasonable. We defined drag (in N), $F_{\mathrm{d}}$ in Eq. (1) and $z\left[x^{\prime}(t)\right]$ in Eq. (2), at a speed of $x^{\prime}(t)$ as:

$$
F_{\mathrm{d}}=1.25\left[\mathrm{x}^{\prime}(t)\right]^{2}
$$

(Fig. 1b) This definition also seems reasonable because the range of difference between this function and Lovvorn et al. (1999)'s function $\left(0.37-0.87 x^{\prime}(t)+1.33\left[x^{\prime}(t)\right]^{2}\right)$ is $-0.37-1.89 \mathrm{~N}$ for speeds less than $4 \mathrm{~m} \mathrm{~s}^{-1}$.

To represent the declining output power strategy depending upon the current depth in the model, we prepared 3 functions: (1) $F_{\mathrm{g}}-F_{\mathrm{b}}+a_{\text {, }}$ that is, $a+\{7.5 /[1+0.1 x(t)]-1.3\}$, (2) $a\left(F_{\mathrm{g}}-F_{\mathrm{b}}\right)$, that is, $a\{7.5 /[1+0.1 \mathrm{x}(t)]$ $-1.3\}$ and (3) $K\{1-\tanh [a x(t)]\}$ (Fig. 2). Therefore, parameters $a$ and $K$ are decision variables made by the animal. The functions (1) and (2) were used for the descent phase and (3) was used for the ascent phase. The functions (1) and (3) represent a moderately-declining pattern of output power, whereas the function (2) represents a rather dramaticallydeclining pattern of output power. For
Table 1. Definition of functions and variables used in the calculations. $x(t)$ : current depth; $x^{\prime}(t)$ : speed

\begin{tabular}{|ll}
\hline Basic functions and variables & \\
Buoyancy (N) & $8.5+7.5 /[1+0.1 x(t)]$ \\
Drag $(\mathrm{N})$ & $1.25\left[x^{\prime}(t)\right]^{2}$ \\
BMR $\left(\mathrm{J} \mathrm{s}^{-1}\right)$ & 8.5 \\
& \\
Stroke frequency patterns & $a$ \\
Constant output power strategy & \\
Declining output power strategies: & $a+\{7.5 /[1+0.1 x(t)]-1.3\}$ \\
Moderately-declining in descending & $a\{7.5 /[1+0.1 x(t)]-1.3\}$ \\
Dramatically-declining while descending & \\
Moderately-declining while ascending & $K\{1-\tanh [\operatorname{ax}(t)]\}$
\end{tabular}

the functions (1) and (2), large a indicates a high stroke frequency, whereas for the function (3) large $K$ indicates a high stroke frequency and large $a$ indicates a large declining rate ('braking') of stroke frequency (Fig. 2). Using the functions described above and Eq. (2), we sought optimal parameters $a$ and $K$ for
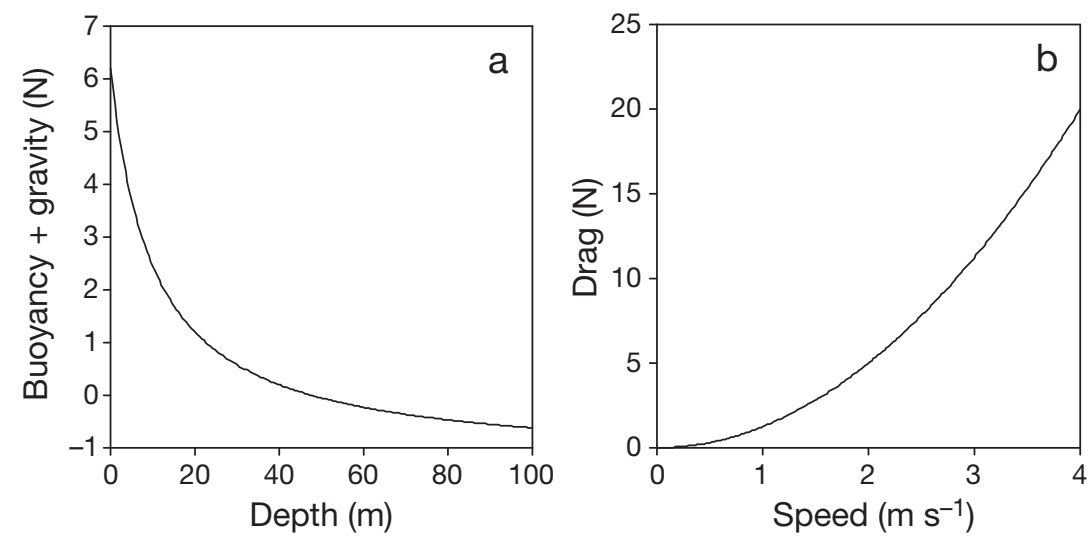

Fig. 1. Functions used in the model. (a) buoyancy and gravity against depth, (b) drag against speed
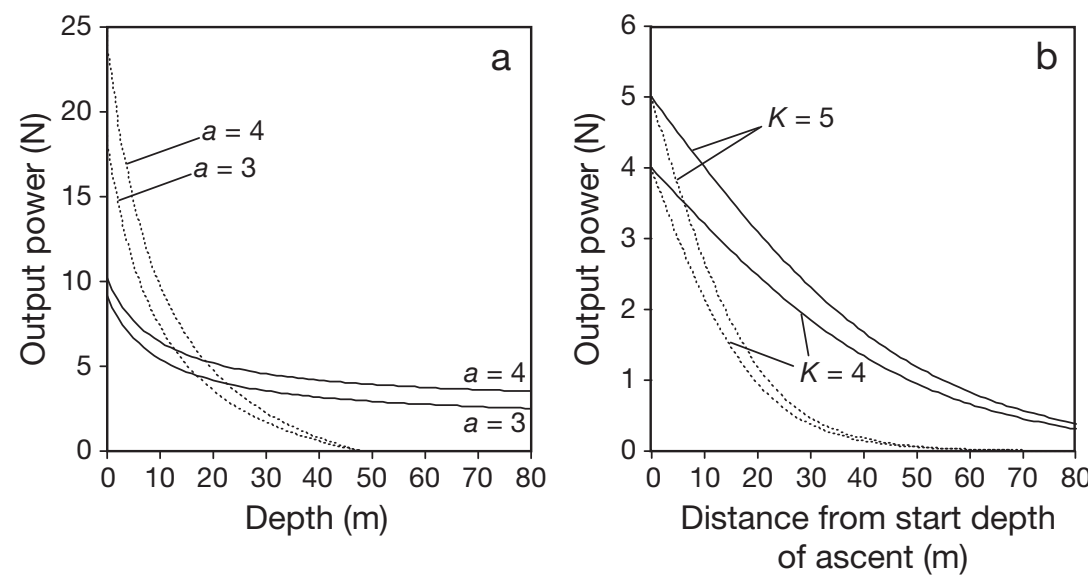

Fig. 2. Functions used to represent patterns of output power and depth. (a) Descending. Solid lines: moderately-declining patterns; dotted lines: dramaticallydeclining patterns. (b) Ascending. Solid lines: $a=0.02$; dotted lines: $a=0.05$; parameter $K$ corresponds to stroke frequency; parameter a corresponds to 'braking' of stroke frequency 
given output power strategies that minimize COT for a given target depth, assuming a BMR of $8.5 \mathrm{~J} \mathrm{~s}^{-1}$. This is the same as that of $1.2 \mathrm{~kg}$ little penguins Eudyptula minor (Bethge et al. 1997). Note that total energetic cost in the model consists of energy used for mechanical work to transport, and for basal metabolism during transport. Next, we compared the minimum COT for a given target depth, reviewing the different output power strategies to find the optimal strategy. Mathematica 5 (Wolfram Research) was used throughout for all computation.

Empirical data-diving data compared with predictions. To compare predictions derived from the models with observed diving behaviour (stroke frequency patterns and swimming speed during diving), we used a data set of diving behaviour obtained from South Georgian shags Phalacrocorax georgianus. Data were collected at Bird Island (54 $00^{\prime} \mathrm{S}, 38^{\circ} 03^{\prime} \mathrm{W}$ ), South Georgia, during January 2005. The complete description of the field methods for this study will be published elsewhere; here we provide only brief details. In short, a data-logger (15 $\mathrm{mm}$ in diameter, $53 \mathrm{~mm}$ long, mass in air $17 \mathrm{~g}$; M190-D2GT, Little Leonardo) was attached in the middle of the lower back of each bird brooding chicks. Device mass was $<1 \%$ of shag body mass and device cross sectional area $\left(177 \mathrm{~mm}^{2}\right)$ was $2 \%$ of cross sectional area of similar sized Japanese cormorant $P$. filamentosus $\left(8652 \mathrm{~mm}^{2}\right.$ ) (Osa 1994). Similar sized radio transmitters deployed in a similar manner, did not appear to disrupt behavior or breeding success of European shags P. aristotelis (Wanless et al. 1991) or Japanese cormorants (Watanuki et al. 2004). The loggers recorded pressure (diving depth) every second $(1 \mathrm{~Hz})$, and surge (tail to head) and heave (ventral to dorsal) acceleration at $64 \mathrm{~Hz}$. Using these records, we could derive stroke frequency patterns and swim speeds during diving. See Watanuki et al. (2005) for details of the procedures used to obtain these diving parameters from such recorded data.

We used dives deeper than $50 \mathrm{~m}$ to test our predictions as changes in behaviour during deep dives should be more readily detectable. Among the 6 birds that we instrumented, 2 males made frequent dives deeper than $50 \mathrm{~m}$, so data from these 2 birds (Shag 1 and Shag 10) were used. Shag 1 made 27 dives during a $9 \mathrm{~h}$ recording period and Shag 10 made 32 dives during a $13 \mathrm{~h}$ recording period.

There are few quantitative differences in features of diving behaviour between these 2 birds. One of the main reasons for this is the differences in practical parameters linking buoyancy, drag and output power patterns between the birds. However, as we could not measure these parameters in practice, we did not discuss the reasons for this in detail.

\section{RESULTS}

\section{Optimal output power models}

\section{Descent phase}

The model predicted that the initial thrust or stroke frequency should decrease during descent as the target depth increased and if the bird adopted a constant or moderately-declining output power strategy; however, it should first decrease then increase if the diver adopted a dramatically declining output strategy (Fig. 3). In comparing the constant and moderatelydeclining output power strategies, divers adopting a constant output power strategy should decrease the initial thrust more than those adopting a moderatelydeclining output power strategy as the target depth becomes deeper (Fig. 3).

The minimum COT declined as the target depth became deeper because of the decreasing buoyancy. The minimum COTs were similar to each other for the 3 output power strategies when the target depth was shallow. However, in the range where the target depth was deep, the moderately-declining output strategy was the best strategy giving the lowest COT (Fig. 4).

The model also predicted how swim speed should change during diving as a result of an adopted output power strategy. Each output power strategy gave a characteristic pattern of swim speed during descent: moderately-increasing speed, constant speed, and decreasing speed, respectively for constant, moderatelydeclining, and dramatically-declining output power strategies (Fig.5).

\section{Ascent phase}

When ascending from shallow depths $(<15 \mathrm{~m})$, the optimal initial thrust should be zero, or the diver

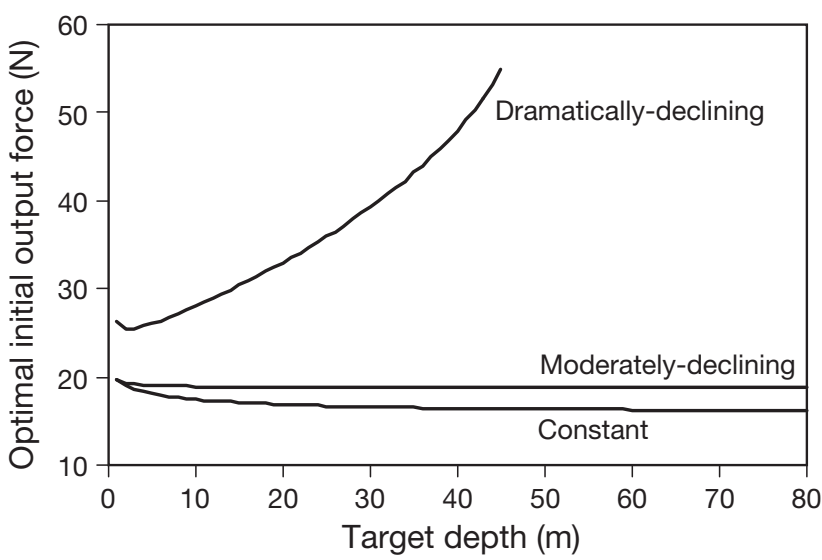

Fig. 3. Optimal initial output force and target depth during descent for each strategy 


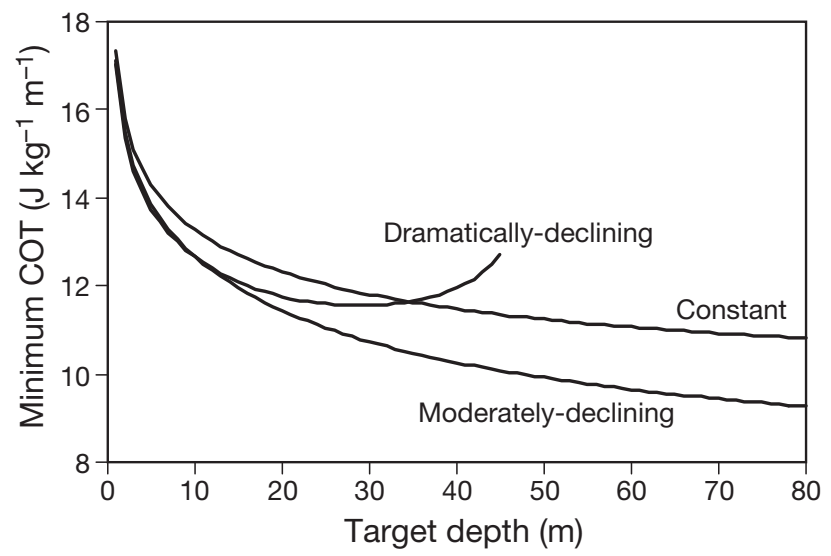

Fig. 4. Minimum cost of transport (COT) and target depth during descent for each strategy. Note moderately-declining output power strategy attains a smaller minimum COT than a constant output power strategy, especially for deeper target depths

should not stroke. When ascending from deeper depths, the optimal initial thrust to ascend should increase with the target depth for the diver adopting the constant output power strategy (Fig. 6). For the diver adopting a declining output power strategy, initial thrust or stroke frequency, that is represented by parameter $K$ in function (3), should decrease and then increase with the target depth. However, the braking force (degree of deceleration), which is represented by parameter $a$, should decrease with the depth from which the diver returns to the surface (Fig. 7).

When returning from shallow depths, the no-stroke strategy, i.e. a constant output strategy, is better, but when returning from greater depths, the declining output power strategy is slightly better than the constant output power strategy (Fig. 8). The minimum COT first decreases and then increases as the start depth of the ascent increases.

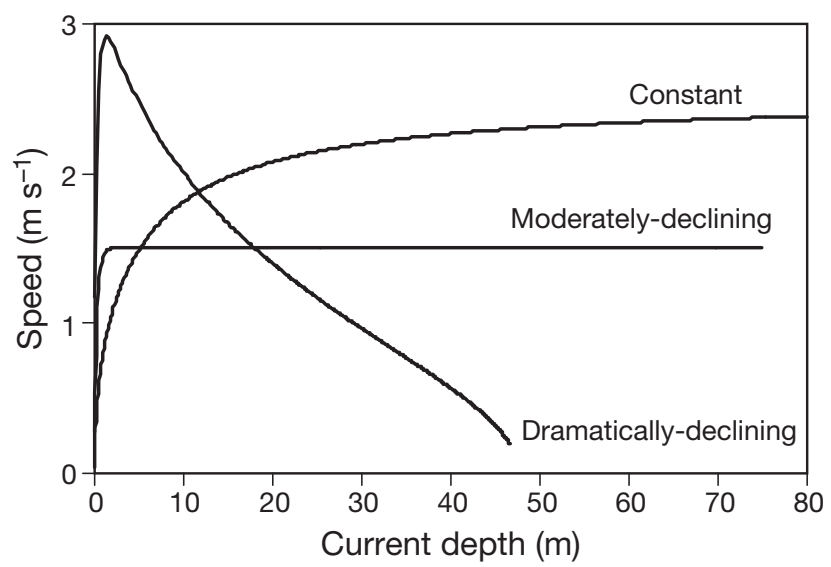

Fig. 5. Changes in swimming speed during descent for each strategy

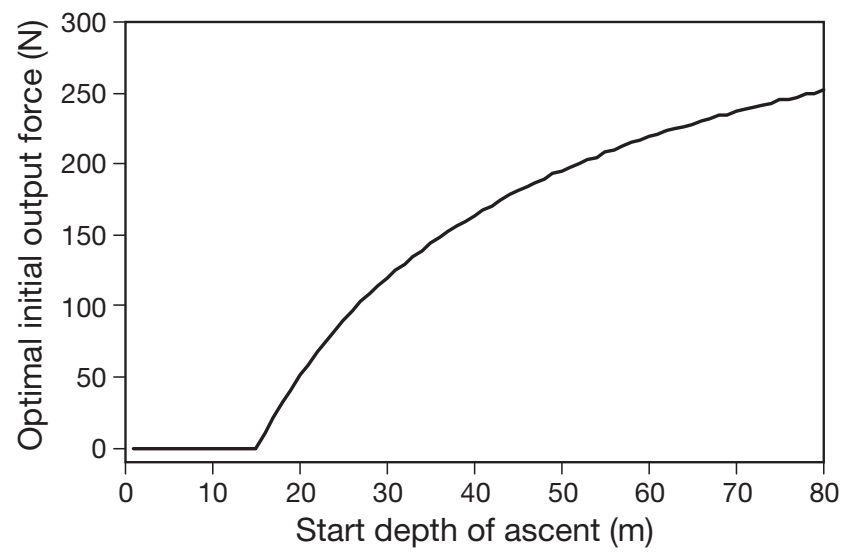

Fig. 6. Optimal initial output force and start depth of ascent for constant output power strategy

Each output power strategy gave a characteristic pattern of swim speed during ascent: moderatelyincreasing speed and decreasing-then-increasing speed for constant and declining output power strategies respectively (Fig. 9).

\section{Roundtrip: descent and ascent}

The minimum COT to make a round trip was large for shallow dives, suggesting that the buoyancy effect was large. Although the difference in COT between constant and declining output power strategies was small for shallow dives, the latter strategy was better for diving in general (Fig. 10).

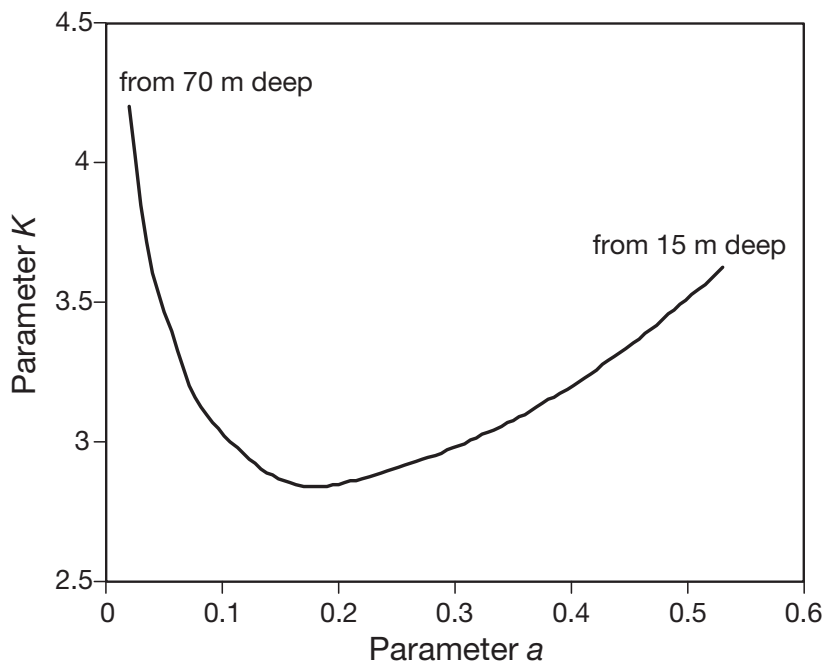

Fig. 7. Optimal parameters $K$ (indicating stroke frequency) and $a$ (indicating declining rate or 'braking' of stroke frequency) for output power during ascent for a given start depth of ascent 


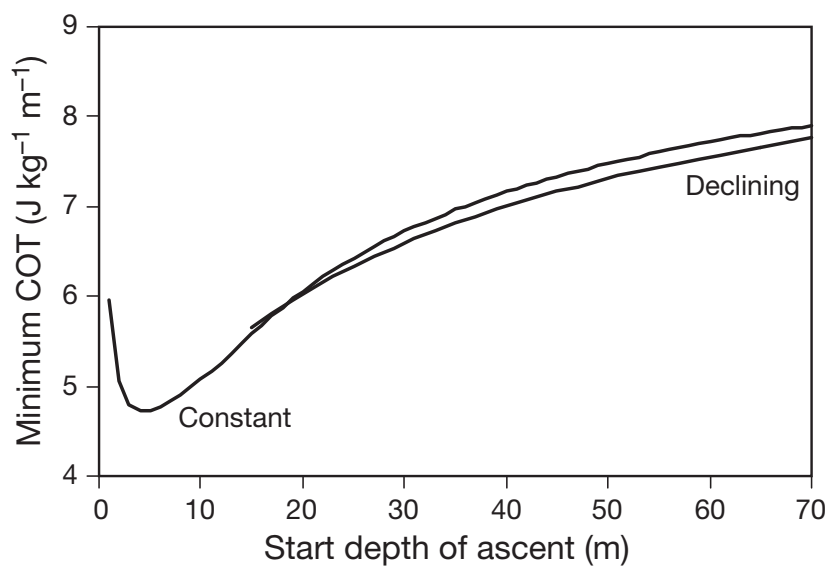

Fig. 8. Minimum cost of transport (COT) and start depth of ascent for strategies with constant and declining stroke frequencies. Note declining output power strategy attains smaller minimum COT than a strategy with a constant output power

\section{Tests of predictions with empirical data}

As described above, our models predict that: (1) output power (stroke frequency), declines during descent and it also declines during ascent in a dive (Figs. 4 \& 8), (2) initial thrust for dives to deeper target depths should be smaller during descent (Fig. 3) but greater during ascent (Fig. 6) and, (3) swim speed should be constant during descent and first decrease or remain constant then increase during ascent (Figs. 5 \& 9). We tested these predictions using the observed diving data (unpubl.) obtained from South Georgian shags.

Mean $( \pm \mathrm{SD})$ body angle during descent and ascent were $-73.3 \pm 3.3$ and $80.0 \pm 4.3^{\circ}$ for Shag 1 and were $-80.0 \pm 4.4$ and $72.4 \pm 3.5^{\circ}$ for Shag 10 ; shags descended and ascended almost vertically. During descent, the absolute amplitude of heave acceleration at each stroke were within a certain range ( 7 to $9 \mathrm{~m} \mathrm{~s}^{-2}$ )

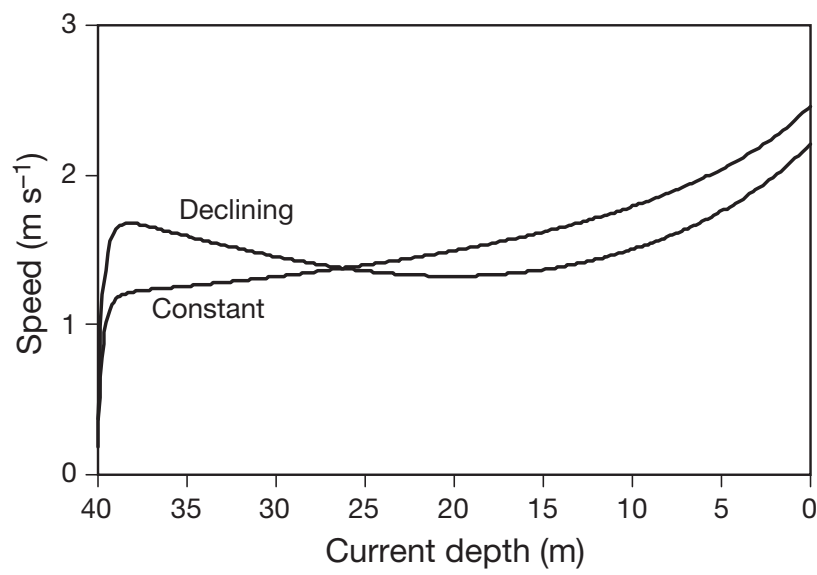

Fig. 9. Changes in swimming speed during ascent for strategies with constant and declining stroke frequency

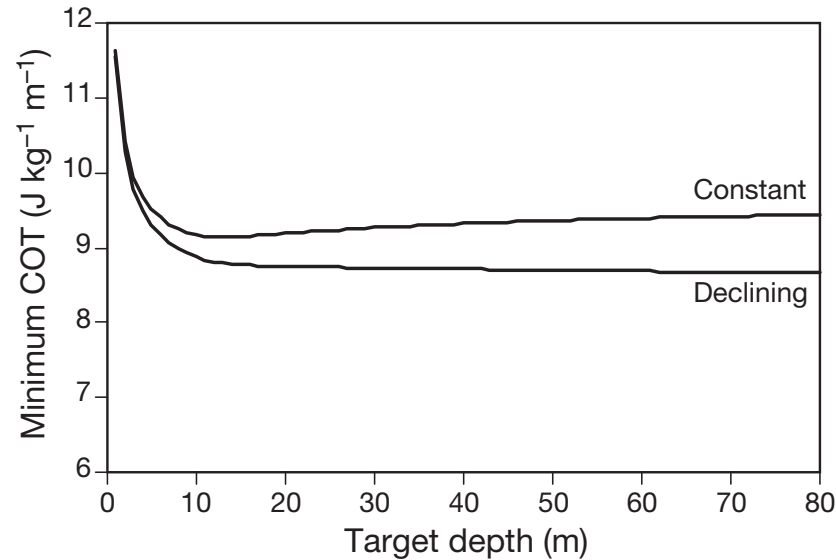

Fig. 10. Minimum cost of transport (COT) for roundtrip and diving depth for strategies with constant and declining stroke frequency

above 40 to $50 \mathrm{~m}$ depths and then decreased to $6 \mathrm{~m} \mathrm{~s}^{-2}$ at $80 \mathrm{~m}$. During powered ascent, minimum heave acceleration was significantly related to depth for both birds, though the coefficients of determination were small (0.088 to 0.135).

During descent, the duration of power strokes increased from 0.12 to $0.15 \mathrm{~s}$ at $10 \mathrm{~m}$ depth, to 0.20 to $0.24 \mathrm{~s}$ at $80 \mathrm{~m}$ depth with a quadratic decelerating function (Fig. 11a, Table 2). Duration of the glide/ recovery increased from 0.14 to $0.16 \mathrm{~s}$ at $10 \mathrm{~m}$ to 0.95 to $1.40 \mathrm{~s}$ at $80 \mathrm{~m}$ with a quadratic accelerating function (Fig. 11b, Table 2). Thus, the frequency of stroke (reciprocal of the sum of the duration of power stroke and glide/recovery) decreased with current depth with a logarithmic decelerating function (Fig. 11c, Table 2). During powered ascent from the bottom (60 to $90 \mathrm{~m}$ ) to 46 to $47 \mathrm{~m}$, the duration of power strokes were within a narrow range $(0.21 \pm 0.03 \mathrm{~s}$ for Shag 1 and $0.22 \pm$ $0.02 \mathrm{~s}$ for Shag 10). The duration of the glide/recovery increased from 0.5 to $1.0 \mathrm{~s}$ at $80 \mathrm{~m}$ to 2.0 to $3.0 \mathrm{~s}$ at $40 \mathrm{~m}$. Thus the frequency of stroke decreased with decreasing current depth linearly for Shag 1 and with a quadratic function for Shag 10 (Fig. 11c, Table 2). These findings indicate that Prediction (1) is supported.

Stroke frequency for the first $5 \mathrm{~m}$ after the beginning of descent or ascent did not correlate significantly with the target depth or start depth of the ascent (Fig. 12), apart for descents made by Shag $10(r=0.78, \mathrm{n}=31$, $\mathrm{p}<0.01$ ), suggesting that Prediction (2) was not fully supported. During descent, the swim speeds of Shag 1 and Shag 10, respectively, increased slightly with increasing depth towards a maximum of $1.9 \pm 0.1$ and $2.0 \pm 0.1 \mathrm{~m} \mathrm{~s}^{-1}$ at $41 \pm 8$ and $51 \pm 11 \mathrm{~m}$, then decreased slightly for both birds (Fig. 13, Table 2). During ascent, swim speed was related to depth using a quadratic function (Fig. 13, Table 2). During powered ascent, swim speeds of Shag 1 and Shag 10, respectively, 

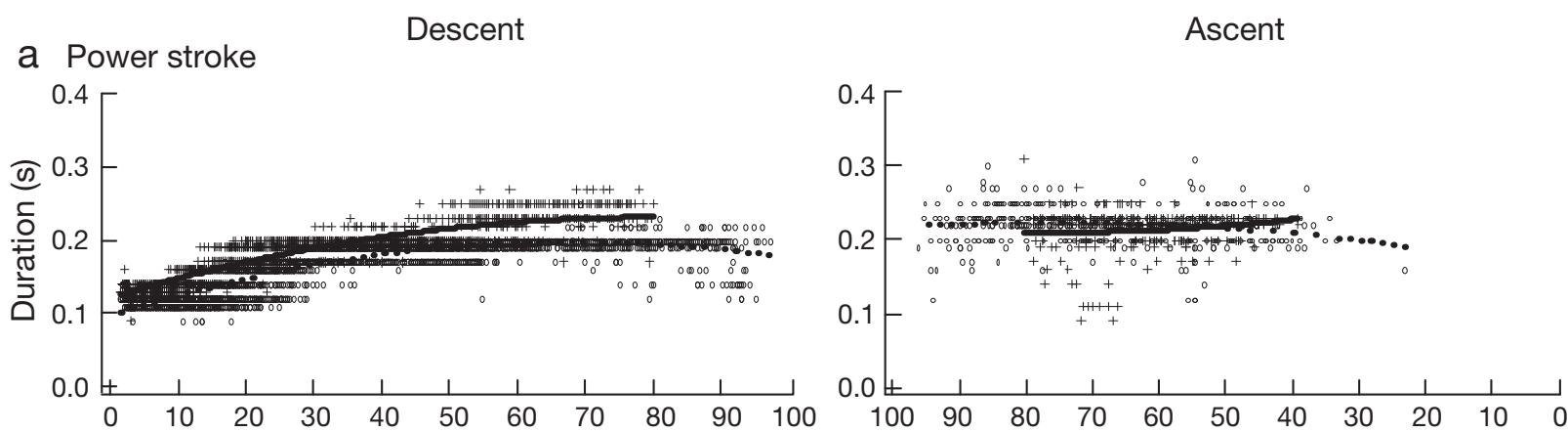

b Glide/recovery
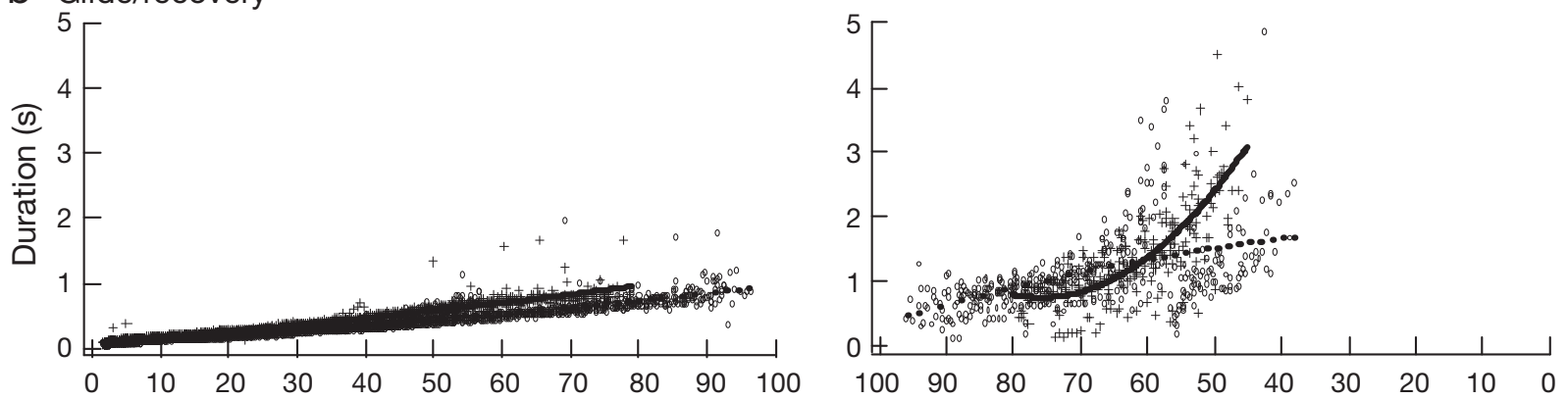

C Stroke frequency
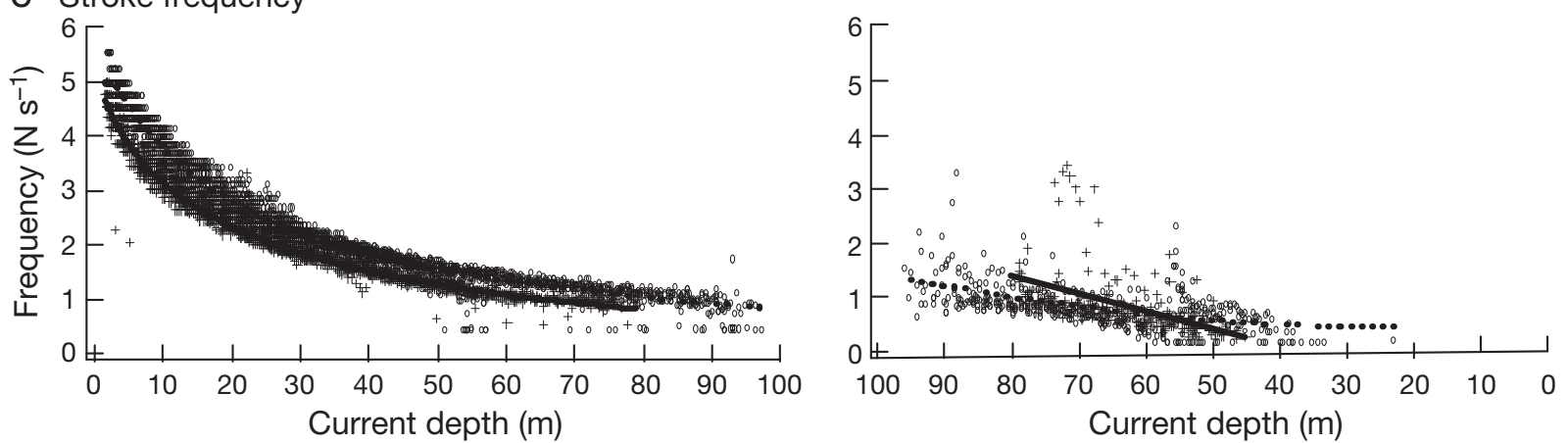

Fig. 11. Phalacrocorax georgianus. Changes of stroke pattern with current depth during descent and ascent: (a) the duration of power stroke, (b) the duration of glide/recovery and (c) the frequency of the power stroke. Dots and crosses indicate the data of each stroke for Shag 1 and Shag 10, respectively. Regression lines are also given (see Table 2). Thick lines: Shag 1, dotted lines: Shag 10

Table 2. Regression equations showing effects of current depth $(\mathrm{m})$ on power stroke duration (s), glide/recovery duration (s), stroke frequency $\left(\mathrm{N} \mathrm{s}^{-1}\right)$ and swim speed $\left(\mathrm{m} \mathrm{s}^{-1}\right)$ in Shag 1 and Shag 10; $x$ : current depth

\begin{tabular}{|c|c|c|c|c|c|c|}
\hline \multirow[t]{2}{*}{ Dependent variables) } & \multicolumn{3}{|c|}{ Shag $1-$} & \multirow[t]{2}{*}{ - Shag 10} & \multirow[b]{2}{*}{$\mathrm{r}^{2}$} & \multirow[b]{2}{*}{$\mathrm{p}$} \\
\hline & $y$ & $r^{2}$ & $\mathrm{p}$ & & & \\
\hline \multicolumn{7}{|l|}{ Descent } \\
\hline Stroke duration & $0.12+0.003 x-1.84 \times 10^{-5} x^{2}$ & 0.86 & $<0.001$ & $0.13+0.002 x-1.45 \times 10^{-5} x^{2}$ & 0.52 & $<0.001$ \\
\hline Glide/recovery & $0.08+0.008 \times 3.56 \times 10^{-5} x^{2}$ & 0.95 & $<0.001$ & $0.08+0.006 x+2.70 \times 10^{-5} x^{2}$ & 0.80 & $<0.001$ \\
\hline Stroke frequency & $5.62-2.54 \log x$ & 0.98 & $<0.001$ & $5.99-2.59 \log x$ & 0.91 & $<0.001$ \\
\hline Speed & $1.61+0.008 x-1.03 \times 10^{-4} x^{2}$ & 0.15 & $<0.001$ & $1.67+0.008 x-0.82 \times 10^{-4} x^{2}$ & 0.17 & $<0.001$ \\
\hline \multicolumn{7}{|l|}{ Ascent } \\
\hline Stroke duration & $0.29-0.002 x+1.33 \times 10^{-5} x^{2}$ & 0.02 & 0.06 & $0.16+0.002 x-1.14 \times 10^{-5} x^{2}$ & 0.03 & $<0.01$ \\
\hline Glide/recovery & $15.06-0.38 x+0.002 x^{2}$ & 0.59 & $<0.001$ & $1.92-2.038 \times 10^{-4} X-1.57 \times 10^{-4} X^{2}$ & 0.26 & $<0.001$ \\
\hline Stroke frequency & $-1.24+0.033 x$ & 0.26 & $<0.001$ & $1.48-0.033 x+3.33 \times 10^{-4} x^{2}$ & 0.27 & $<0.001$ \\
\hline Speed & $2.42-0.032 x+3.47 \times 10^{-4} x^{2}$ & 0.62 & $<0.001$ & $2.36-0.019 x+1.39 \times 10^{-4} x^{2}$ & 0.40 & $<0.001$ \\
\hline
\end{tabular}



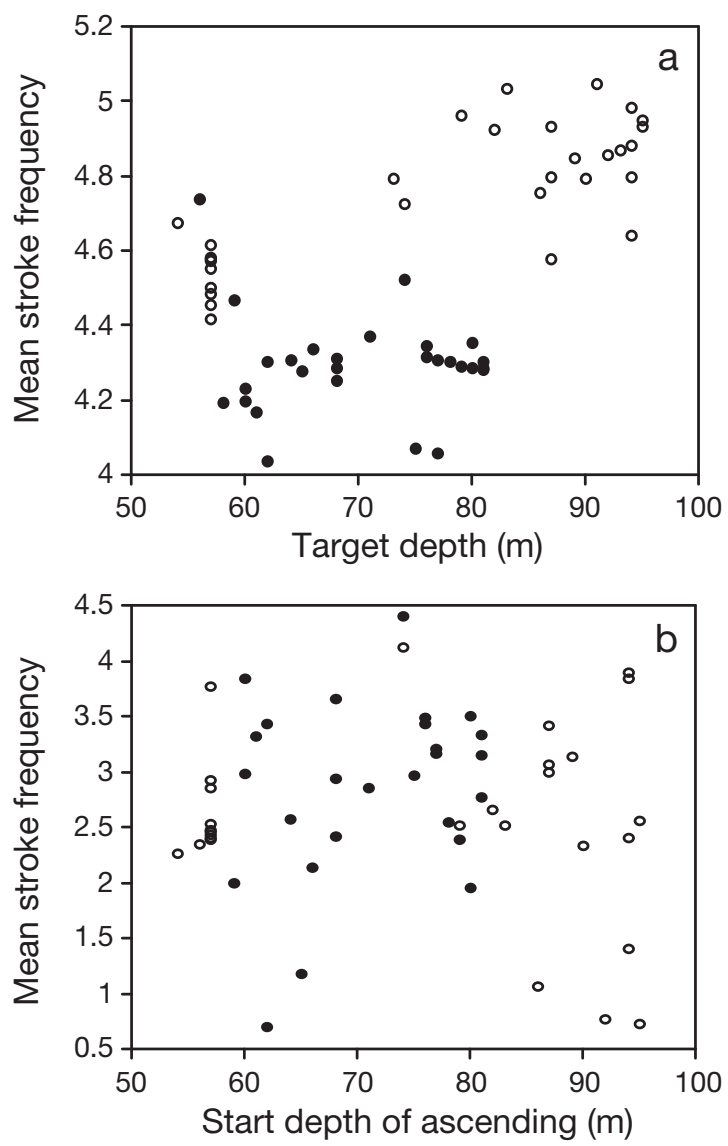

Fig. 12. Phalacrocorax georgianus. Depth and mean stroke frequency for first $5 \mathrm{~m}$ after start of (a) descent, and (b) ascent for Shag $1(0)$ and Shag $10(\bullet)$

decreased with decreasing depth towards a minimum of $1.5 \pm 0.1$ and $1.6 \pm 0.2 \mathrm{~m} \mathrm{~s}^{-1}$ at $45 \pm 6$ and $47 \pm 10 \mathrm{~m}$ depths. At around these depths both birds stopped strokes (see also Fig. 13a). Then swim speed increased quickly during passive ascent up to $2.5 \mathrm{~m} \mathrm{~s}^{-1}$ near the surface (Fig. 13). These patterns are consistent with Prediction (3).

\section{DISCUSSION}

\section{Assumptions used in the model}

In the present model, we assumed that divers minimize their COT, or energy used per unit distance during diving. Several studies report that divers prefer swimming speeds where the COT is minimized (e.g. Culik \& Wilson 1991, Culik et al. 1991, Bethge et al. 1997, Wilson et al. 2002), suggesting this assumption is realistic. However, it should be noted that minimizing this cost maximizes the energy or time spent for other activities during the dive cycle, such as feeding.
We also assumed vertical diving, although many seabirds do not always dive vertically. When an animal dives obliquely, the effect of buoyancy becomes small and the time needed to reach a target depth becomes long, compared with vertical diving. This situation can be expressed in the present model by using a different buoyancy function and assuming great diving depth. Therefore, as long as the general shape of the buoyancy function remains as in Fig. 1a, the qualitative features of the results derived from the model should be maintained.

The divers in the model are assumed to control output power continuously and smoothly, hence move steadily, throughout diving. In practice, the birds stroke and glide, hence repeat acceleration and deceleration and lose inertial work (Lovvorn 2001). If the inertial work is proportional to stroke frequency, qualitative results derived from the present model is maintained. We also assume that the stroke frequency is proportional to output power. The output power is accumulation of force produced by each stroke during diving, and divers can adjust both the magnitude of the force and frequency of stroke to control output power during diving. We consider that the divers in the model control stroke frequency rather than the force produced by a stroke. This seems an appropriate assumption, because mean forward force produced by a stroke does not vary during diving (Lovvorn et al. 2004). Shags did not change amplitude of maximum heave acceleration at power stroke with the current depths while descending. This indirect evidence also indicates that bird change stroke frequency, but not the force of stroke. Therefore, our assumptions used in the model are appropriate when investigating general features of optimal stroke frequency patterns during diving.

\section{Optimal stroke frequency patterns}

The present study shows that divers should reduce their output power, or stroke frequency, during the descent and ascent phases of a dive, i.e. divers should decrease output power at current depth while descending to a deeper depth and while ascending to shallower depth during a dive (Figs. 4 \& 8). This means that the constant, or increasing, output power strategy during a dive may result in a reduced time to travel, but not necessarily pay for the increased energy consumption itself or against the increased drag force. Many seabird species reduce their stroke frequency during the descent phase of a dive (e.g. van Dam et al. 2002, Watanuki et al. 2003, 2005, 2006, Lovvorn et al. 2004, Sato et al. 2004, Kato et al. 2006, Watanuki \& Sato 2008). South Georgian shags in the present 

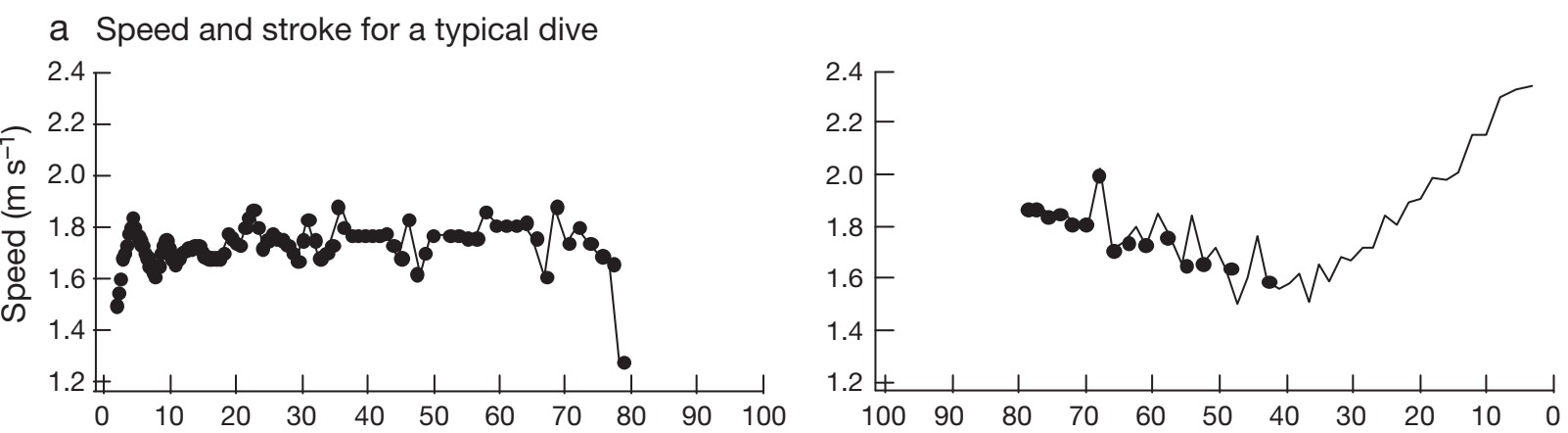

\section{b Speed for all $1 \mathrm{~s}$ samples}
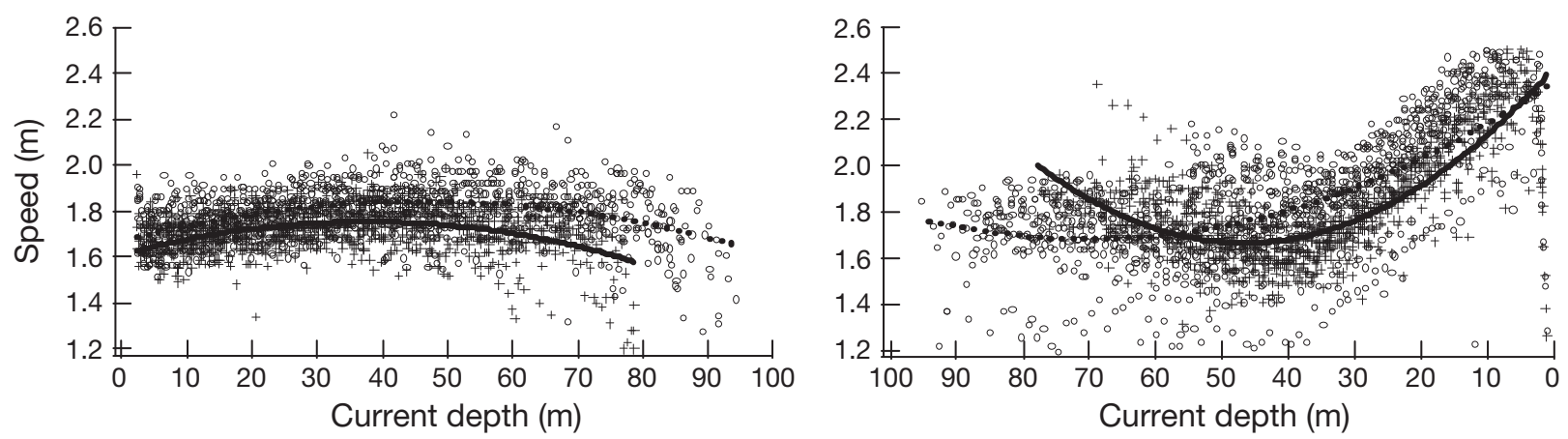

Fig. 13. Phalacrocorax georgianus. (a) Changes in swimming speed (line) with depth during descent and ascent for a typical dive of Shag 1. Start of each stroke is shown by closed circle. (b) Changes in swimming speed with depth for all samples during descent and ascent. Dots and crosses in (b) indicate the data of each 1 s sampling interval for Shag 1 and Shag 10, respectively. Regression lines are also given (see Table 2). Thick lines: Shag 1, dotted lines: Shag 10

study actually decreased stroke frequency with current depth logarithmically while descending, indicating that the birds regulate the stroke frequency to compensate the change of buoyancy with current depth. It is known that deep diving (> 50 m) Brünnich's guillemots decrease stroke frequency while ascending from depths deeper than those where they have negative buoyancy (Watanuki et al. 2003). However, it appears true that there are a few species that do not show such a tendency (e.g. Watanuki et al. 2006, Kato et al. 2006). Our model also indicates that adopting the cost saving strategy of declining stroke frequency instead of using a constant stroke frequency was small; especially when the dive depth was shallow. This suggests that shallow diving animals may not decrease their stroke frequency during diving, and this may explain why some seabirds appear to adopt a strategy of using a constant stroke frequency during shallow diving.

When comparing the strategies with a moderatelydeclining stroke frequency and a dramatically-declining stroke frequency, our model suggested that the COT was similar when the target depth was shallow $(<15 \mathrm{~m})$ but that the former strategy was better when the target depth was deep $(>15 \mathrm{~m})$. However, it was hard to distinguish moderately- and dramatically- declining strategies; the difference between these 2 strategies appeared to in the change in swimming speed during descent. The former gave a more or less constant swim speed, whereas the latter gave a decreasing speed. Observed swimming speeds during descent in South Georgian shags were more or less constant, suggesting that the birds decreased their stroke frequency 'moderately.' In other species, both constant speed and moderately-increasing speed can be observed during descent to shallow dive depths (e.g. Watanuki et al. 2006). However, this is not surprising, because, as described above, a strategy with a constant stroke frequency gives a moderatelyincreasing speed during descent and is therefore as efficient as a strategy with a moderately-declining stroke frequency.

During the ascent phase, our model suggests that divers should not stroke to return from shallow depths to the surface. This is not surprising because divers can use buoyancy to ascend. While ascending from deeper waters, our model predicts that swimming speed should first decrease, or remain constant, then increase. This pattern is found not only in South Georgian shags shown in the present study but also in Brünnich's guillemots (Watanuki et al. 2003) and king penguins Aptenodytes patagonicus (Sato et al. 2002) 
ascending from deep depths presumably below the depths of neutral buoyancy, suggesting that birds adjust their stroke frequency to minimize or at least decrease the COT.

Our model predicted that the stroke frequency at a given depth should slightly decrease as the target depth becomes deeper; if the diver adopts a constant or moderately-declining stroke frequency strategy. However, our South Georgian shags did not show such a tendency or showed a contrary tendency, although they seemed to adopt a moderately-declining stroke frequency strategy. It is known that common guillemots Uria aalge did not change amplitude of maximum heave acceleration at power stroke nor stroke frequency at a give depth according to the target depths (Watanuki \& Sato 2008). One possible reason for this inconsistency is that buoyancy for diving seabirds is not always constant, irrespective of target depth. Diving birds need an oxygen reservoir and store variable amounts of air (oxygen) as gas in their lungs or air sac. Therefore, it is likely that in preparing to dive deeper, birds have greater buoyancy due to greater reservoirs of air as gas. Birds preparing to make shallow dives will be less buoyant and have lower reserves of air (Sato et al. 2002, Wilson 2003). For deeper diving birds, initial stroke frequency should increase as the target depth becomes deeper, which may mask the effects predicted by our model. If this is the case, diving animals that do not store oxygen as gas, such as marine mammals that store oxygen in solution in the body tissues, should show the predicted pattern in the relationship between target depth and initial stroke frequency. Although we did not consider this in our model, the control of buoyancy depending on target depths is an interesting issue because this can be an important factor affecting the energy budget during diving. For example, it is suggested that Crozet shags Phalacrocorax melanogenis and Kerguelen shags $P$. verrucosus may control neutral buoyancy depth in relation to targeted dive depth through respiratory air volume adjustment (Cook et al. 2008). This adjustment should be useful to reduce the cost of transport.

Our model and findings are applicable not only to seabirds, but also to marine mammals. For marine mammals such as seals, the effects of buoyancy should be apparent not through volume of air in the body but through fat under the skin; a large amount of fat corresponds to high buoyancy. It is likely that the amount of fat can be affected by body condition or season during a year. Therefore, our model predicts that diving parameters such as stroke frequency and swimming speed in marine mammals should be changed according to body condition (i.e. fat or lean) and periods (i.e. before and after moulting).
In conclusion, a strategy with declining output power or stroke frequency is indeed efficient and will minimize the COT while diving. It should be noted, however, that the disadvantage of a constant output power pattern is relatively small, especially at shallow depths. Therefore, a strategy with constant output power or stroke frequency, irrespective of current depth, could be almost as efficient and therefore a viable and nearly equivalent strategy, depending upon environmental and physiological conditions. In particular, during the descent phase, a relatively constant swimming speed can be achieved with a moderately-declining stroke frequency, whereas an increasing swimming speed can be achieved with a constant stroke frequency; both of these strategies can be observed in nature. These results suggest that diving seabirds adjust and control their stroke frequency pattern while diving, generating the observed changes in swimming speed with minimum COT.

Acknowledgements. We are grateful to personnel at the British Antarctic Survey (BAS) Bird Island Research Station during 2004 and 2005, for their support during the field study, and H. Tanaka for helping analyses of acceleration. This study was supported by Grant-in-Aid for Scientific Research (KAKENHI 19570027 and 20310016) of the Japanese Society for the Promotion of Science, and 21st Century COE program of 'Neo-Science of Natural History' led by N. Okada. The fieldwork was approved by BAS and the University of Cambridge Animal Ethics Board.

\section{LITERATURE CITED}

Bethge P, Nicol S, Culik BM, Wison RP (1997) Diving behaviour and energetics in breeding little penguins (Eudyptula minor). J Zool (Lond) 242:483-502

Carbone C, Houston AI (1996) The allocation of time over the dive cycle: an approach based on aerobic and anaerobic respiration. Anim Behav 51:1247-1255

Cook TR, Bailleul F, Lescroël A, Tremblay Y, Bost CA (2008) Crossing the frontier: vertical transit rates of deep diving cormorants reveal depth zone of neutral buoyancy. Mar Biol 154:383-391

Culik BM, Wilson RP (1991) Swimming energetics and performance of instrumented Adelie penguins (Pygoscelis adeliae). J Exp Biol 158:355-368

Culik BM, Wilson RP, Danfeld R, Adelung D, Spairani HJ, Coria NR (1991) Pygoscelid penguins in a swim canal. Polar Biol 11:277-282

> Heath JP, Gilchrist HG, Ydenberg RC (2006) Regulation of stroke pattern and swim speed across a range of current velocities: diving by common eiders wintering in polynyas in the Canadian Arctic. J Exp Biol 209:3974-3983

> Heithaus MR, Frid A (2003) Optimal diving under the risk of predation. J Theor Biol 223:79-92

Houston AI, Carbone C (1992) The optimal allocation of time during the diving cycle. Behav Ecol 3:255-265

Kato A, Ropert-Coudert Y, Gremillet D, Cannell B (2006) Locomotion and foraging strategy in food-propelled and wing-propelled shallow-diving seabirds. Mar Ecol Prog 
Ser 308:293-301

Kramer DL (1988) The behavioural ecology of air breathing by aquatic animals. Can J Zool 66:89-94

Lovvorn JR (2001) Upstroke thrust, drag effects, and strokeglide cycles in wing-propelled swimming by birds. Am Zool 41:154-165

Lovvorn JR, Jones DR, Blake RW (1991) Mechanics of underwater locomotion in diving ducks: drag, buoyancy and acceleration in a size gradient of species. J Exp Biol 159: 89-108

Lovvorn JR, Croll DA, Liggins G (1999) Mechanical versus physiological determinants of swimming speeds in diving Brünnich's guillemots. J Exp Biol 202:1741-1752

Lovvorn JR, Watanuki Y, Kato A, Naito Y, Liggins GA (2004) Stroke patterns and regulation of swim speed and energy cost in free-ranging Brünnich's guillemots. J Exp Biol 207: 4679-4695

Mori Y (1998a) The optimal patch use in divers: optimal time budget and the number of dive cycles during bout. J Theor Biol 190:187-199

Mori Y (1998b) Optimal choice of foraging depth in divers. J Zool (Lond) 245:279-283

Mori Y (1999) The optimal allocation of time and respiratory metabolism over the dive cycle. Behav Ecol 10:155-160

> Mori Y (2002a) Optimal diving behaviour for foraging in relation to body size. J Evol Biol 15:269-276

Mori Y (2002b) An application of optimal diving models to diving behaviour of Brünnich's guillemots. Anim Behav 64:739-745

Osa Y (1994) Functional morphology of diving and flying seabirds. PhD thesis, Tokyo Fisheries University.

Sato K, Naito Y, Kato A, Niizuma Y and others (2002) Buoyancy and maximal diving depth in penguins: Do they control inhaling air volume? J Exp Biol 205:1189-1197

Sato K, Charrassin JB, Bost CA, Naito Y (2004) Why do macaroni penguins choose shallow body angles that result in longer descent and ascent durations? J Exp Biol 207: 4057-4065

Sato K, Ponganis PJ, Habara Y, Naito Y (2005) Emperor penguins adjust swim speed according to the above-water height of ice holes thorough which they exit. J Exp Biol 208:2549-2554

Stephens DW, Krebs JR (1986) Foraging theory. Princeton

Submitted: August 5, 2009; Accepted: December 11, 2009
University Press, Princeton

Stephens DW, Brown JS, Ydenberg RC (2007) Foraging. University of Chicago Press, Chicago

> Thompson D, Fedak MA (2001) How long should a dive last? A simple model of foraging decisions by breath-hold divers in a patchy environment. Anim Behav 61:287-296

> van Dam RP, Ponganis PJ, Ponganis KV, Levenson DH, Marshall G (2002) Stroke frequencies of emperor penguins diving under sea ice. J Exp Biol 205:3769-3774

- Wanless S, Harris MP, Morris JA (1991) Foraging range and feeding locations of shags Phalacrocorax aristotelis during chick rearing. Ibis 133:30-36

> Watanuki Y, Sato K (2008) Dive angle, swim speed and wing stroke during shallow and deep dives in Common Murres and Rhinoceros Auklets. Ornithol Sci 7:15-28

> Watanuki Y, Niizuma Y, Gabrielsen GW, Sato K, Naito Y (2003) Stroke and glide of wing-propelled divers: deep diving seabirds adjust surge frequency to buoyancy change with depth. Proc Biol Sci 270:483-488

> Watanuki Y, Ishikawa K, Takahashi A, Kato A (2004) Foraging behavior of a generalist marine top predator, Japanese Cormorants, in years of demersal vs. epipelagic prey. Mar Biol 145:427-434

Watanuki Y, Takahashi A, Daunt F, Wanless S, Harris M, Sato K, Naito Y (2005) Regulation of stroke and glide in a footpropelled avian diver. J Exp Biol 208:2207-2216

Watanuki Y, Wanless S, Harris M, Lovvorn JR, Miyazaki M, Tanaka H, Sato K (2006) Swim speeds and stroke patterns in wing-propelled divers: a comparison among alcids and penguins. J Exp Biol 209:1217-1230

Wilson RP (2003) Penguins predict their performance. Mar Ecol Prog Ser 249:305-310

Wilson RP, Wilson MP (1988) Foraging behaviour four sympatric cormorants. J Anim Ecol 57:943-955

Wilson RP, Hustler K, Ryan PG, Burger AE, Nöldeke EC (1992) Diving birds in cold water: Do Archimedes and Boyle determine energetic costs? Am Nat 140:179-200

> Wilson RP, Ropert-Coudert Y, Kato A (2002) Rush and grab strategies in foraging marine endotherms: the case for haste in penguins. Anim Behav 63:85-90

Ydenberg RC, Clark CW (1989) Aerobiosis and anaerobiosis during diving by western grebes: an optimal foraging approach. J Theor Biol 139:437-449

Proofs received from author(s): March 7, 2010 